Published in final edited form as:

Eur J Pharmacol. 2016 October 15; 789: 1-7. doi:10.1016/j.ejphar.2016.06.054.

\title{
Chronic $\beta_{1}$-Adrenoceptor Blockade Impairs Ischaemic Tolerance and Preconditioning in Murine Myocardium
}

\author{
Louise See Hoe ${ }^{a, 1}$, Jan M Schilling ${ }^{b, c, 1}$, Anna R Busijab,c, Kristofer J. Haushalter ${ }^{b, c, d}$, \\ Victoria Ozberk $^{\mathrm{a}}$, Malik M. Keshwani ${ }^{\mathrm{e}}$, David M. Roth ${ }^{\mathrm{b}, \mathrm{c}}$, Eugene Du Toit ${ }^{\mathrm{a}}$, John P. \\ Headrick $^{a}$, Hemal H. Patel ${ }^{b, c}$, and Jason N. Peart ${ }^{a,{ }^{*}}$ \\ aHeart Foundation Research Centre, Griffith Health Institute, Griffith University, Southport Q 4222 \\ Australia \\ bVA San Diego Healthcare System, San Diego, USA \\ 'Department of Anesthesiology, University of California San Diego, USA \\ ${ }^{\mathrm{d} C h e m i s t r y}$ and Biochemistry, University of California San Diego, USA \\ ePharmacology, University of California San Diego, USA
}

\begin{abstract}
$\beta$-adrenoceptor antagonists are commonly used in ischaemic heart disease (IHD) patients, yet may impair signalling and efficacy of 'cardioprotective' interventions. We assessed effects of chronic $\beta_{1}$-adrenoceptor antagonism on myocardial resistance to ischemia-reperfusion (IR) injury and the ability of cardioprotective interventions [classic ischaemic preconditioning (IPC); novel sustained ligand-activated preconditioning (SLP)] to reduce IR injury in murine hearts.

Young male C57B1/6 mice were untreated or received atenolol ( $0.5 \mathrm{~g} / \mathrm{l}$ in drinking water) for 4 weeks. Subsequently two cardioprotective stimuli were evaluated: morphine pellets implanted (to induce SLP, controls received placebo) 5 days prior to Langendorff heart perfusion, and IPC in perfused hearts $(3 \times 1.5 \mathrm{~min}$ ischemia/2 min reperfusion).

Atenolol significantly reduced in vivo heart rate. Untreated control hearts exhibited substantial left ventricular dysfunction ( $\sim 50 \%$ pressure development recovery, $\sim 20 \mathrm{mmHg}$ diastolic pressure rise) with significant release of lactate dehydrogenase (LDH, tissue injury indicator) after $25 \mathrm{~min}$
\end{abstract}

\footnotetext{
*Corresponding Author: Dr Jason N. Peart. Heart Foundation Research Centre, Griffith University, Gold Coast Campus. Parklands Drive, Parklands 4222 QLD Australia. Tel.: +61 07555 28357. j.peart@ griffith.edu.au.

${ }^{1}$ Denotes Co-authorship (First)

Publisher's Disclaimer: This is a PDF file of an unedited manuscript that has been accepted for publication. As a service to our customers we are providing this early version of the manuscript. The manuscript will undergo copyediting, typesetting, and review of the resulting proof before it is published in its final citable form. Please note that during the production process errors may be discovered which could affect the content, and all legal disclaimers that apply to the journal pertain.

Authorship Contributions

Participated in research design: See Hoe, Schilling, Busija, Keshwani, Haushalter, Roth, Du Toit, Patel, Headrick, Peart. Conducted experiments: See Hoe, Schilling, Busija, Ozberk, Peart.

Performed data analysis: See Hoe, Schilling, Busija, Haushalter, Keshwani, Headrick, Peart. Wrote/contributed to writing of the manuscript: See Hoe, Schilling, Roth, Du Toit, Patel, Headrick, Peart.

Other: Patel, Roth, Peart and Headrick acquired funding for research.

Disclosures

None.
} 
ischemia/45 min reperfusion. Contractile dysfunction and elevated LDH were reduced $>50 \%$ with IPC and SLP. While atenolol treatment did not modify baseline contractile function, postischaemic function was significantly depressed compared to untreated hearts. Atenolol pretreatment abolished beneficial effects of IPC, whereas SLP protection was preserved.

These data indicate that chronic $\beta_{1}$-adrenoceptor blockade can exert negative effects on functional IR tolerance and negate conventional IPC (implicating $\beta_{1}$-adrenoceptors in IR injury and IPC signalling). However, novel morphine-induced SLP is resistant to inhibition by $\beta_{1}$-adrenoceptor antagonism.

\section{Keywords}

$\beta$-adrenoceptors; cardiac ischemia; cardiovascular drugs; ischemia-reperfusion injury; morphine

\section{Introduction}

Efficacious adjunctive cardioprotection to limit infarct size is a clinically desirable yet largely unfulfilled goal. Clinical translation of protective modalities has achieved limited success, including interventions derived from pre- and post-conditioning phenomena, with modest outcomes contrasting profound protection experimentally (Ferdinandy et al., 2007; Kloner and Schwartz Longacre, 2012; Ludman et al., 2010). Recent trials of post- and remote-conditioning support cardioprotection, with $20-40 \%$ reductions in markers of infarct size (Bøtker et al., 2010; Lønborg et al., 2010; Thibault et al., 2008); however, this is contrasted with $75-80 \%$ reduction observed in pre-clinical models. Reduced clinical efficacies may reflect in part confounding influences of age, common co-morbidities and pharmaceuticals, each negatively impacting upon transduction and efficacies of conventional protective stimuli (Ferdinandy et al., 2007; Peart and Headrick, 2009). Knowledge that conventional responses, typically involving so-called RISK signalling (Hausenloy and Yellon, 2004; Ludman et al., 2010), may be rendered less effective in cohorts requiring cardioprotection (AMI patients $>55$ years of age, with underpinning or co-morbid conditions of obesity, dyslipidaemia, diabetes, hypertension or hypertrophy) demands a more strategic approach to clinical cardioprotection. For example, novel SLP mediates long-lasting protection via distinct signalling (Peart and Gross, 2006; Peart et al., 2011), is resistant to the negative effects of aging (Peart and Gross, 2004), and resultant protection may exceed that with conventional pre- and post-conditioning. Whether the intervention is sensitive to common cardiovascular drugs is unknown.

$\beta$-adrenoceptor antagonists are one of the most widely prescribed classes of drugs in IHD patients with well-established 'anti-ischaemic' effects (reduced heart rate, contractility and afterload) valuable in reducing symptoms of angina, and in the treatment of arrhythmias, congestive cardiomyopathy and AMI. $\beta$-blockade in AMI appears to lower mortality, reducing sudden cardiac death and re-infarction (Freemantle et al., 1999; Frishman et al., 1984). More than $90 \%$ of US AMI patients are thus treated acutely with $\beta$-blockers (Floyd et al., 2009), while many patients at risk of AMI (hypertensives, angina patients) may take $\beta$ AR blockers chronically. This widespread $\beta$-blocker use may influence the efficacy of protective interventions aimed at reducing infarct size (Ferdinandy et al., 2007; Peart and 
Headrick, 2009). However, effects of pre-ischaemic $\beta$-adrenoceptor blockade on IR injury and mechanisms of cardioprotection are mixed, with evidence that $\beta$-adrenoceptor inhibition can be either protective (Asanuma et al., 2004; Kimura-Kurosawa et al., 2007; Schwarz et al., 2003; Spear et al., 2007; Suematsu et al., 2002, 2004) or injurious (Arnold et al., 2007; Park et al., 2011; Spear et al., 2007;), and impair other cardioprotective interventions (Lange et al., 2006; Lochner et al., 1999; Mallet et al., 2006; Spear et al., 2007; Suematsu et al., $2002,2004)$. These effects may reflect differential roles of $\beta_{1}$ - and $\beta_{2}$-adrenoceptors in cardiac injury $v s$. protection, together with the timing and chronicity of $\beta$-adrenoceptor blockade. We here assess effects of chronic antagonism with $\beta_{1}$-selective drug, atenolol, a commonly prescribed $\beta$-blocker, on ischaemic tolerance and the protective efficacies of conventional IPC and novel SLP in healthy murine myocardium. Cardioprotection via IPC mechanisms are reportedly dependent upon $\beta_{1}$-adrenoceptor activation and consequential signalling (Lochner et al., 1999; Spear et al., 2007). As prior studies have implicated $\beta$-AR activation as a mechanism in archetypal cardioprotection, such as IPC, we thus hypothesise that chronic $\beta_{1}$-blockade with atenolol will attenuate the protective effects of IPC..

\section{Materials and Methods}

\subsection{Chemicals}

Slow-release morphine and placebo pellets were obtained from the National Institute of Drug Abuse (Bethesda, MD) or Murthy Pharmaceuticals (Lexington, KY). All other chemicals were purchased from Sigma-Aldrich (St. Louis, MO).

\subsection{Animals}

Investigations conformed to the guidelines of the Animal Ethics Committee of Griffith University (accredited by the Queensland Government, Department of Primary Industries and Fisheries under the guidelines of "The Animal Care and Protection Act 2001, Section 757", AEC number MSC/04/13 licensed to Jason N. Peart) and the Australian Code for the Care and Use of Animals for Scientific Purposes. Studies performed at the Veteran Affairs Hospital San Diego adhered to regulations of the Veterans Affairs San Diego Healthcare System Institutional Animal Care and Use Committee (IACUC), in accordance with the National Institute of Health Guide for the Care and Use of Laboratory Animals (Protocol \#13-005, licensed to Hemal H. Patel). Mice were acquired from the Australian Research Centre (ARC, Adelaide, South Australia) or Jackson Laboratories (Sacramento, California). All animal care and procedures were carried out as humane as possible to minimise suffering. Studies involving live animals are reported in accordance with the ARRIVE guidelines. Mice were housed in approved indoor animal facilities at Griffith University and the Veteran Affairs Hospital (San Diego) that maintained an artificial 12-hour day/night lighting cycle at a constant temperature of $21^{\circ} \mathrm{C}(40 \%$ humidity). A maximum of four mice were housed per cage, with ad libitum access to fresh standard chow and water (regardless of treatment), and provided with environmental enrichment. Daily monitoring of health and wellbeing of mice was carried out at both facilities for the duration of treatment and housing.

Young ( 8 week) male C57B1/6 mice were either untreated or atenolol-treated $(0.5 \mathrm{~g} / \mathrm{l}$ in drinking water) for a period of 4 weeks prior to experimentation. Based on daily water 
intake ( $\sim 0.15 \mathrm{ml} / \mathrm{g} / \mathrm{day}$ ) (Mei et al., 2010; Williams et al., 2003), this equates to $\sim 75 \mathrm{mg} / \mathrm{kg}$ / day. A total of 120 animals were used for this study; 62 untreated and 58 atenolol-treated. Groups were further subdivided based upon preconditioning stimulus employed. Untreated and atenolol-treated mice were implanted with placebo or morphine pellets 5 days prior to experimentation (see below). Experimental groups are: untreated (Control), atenolol treated (Atenolol), IPC in control (IPC) and atenolol-treated (Atl+IPC) hearts, and SLP in control (SLP) and atenolol-treated (Atl+SLP) hearts.

\subsection{SLP Induction}

Mice were briefly anaesthetised with isoflurane, and using aseptic technique a small incision was made at the base of the neck. Placebo or morphine $(75 \mathrm{mg})$ pellets were inserted in the dorsal subcutaneous space and the site closed with $9 \mathrm{~mm}$ wound clips. Pellets were left in place for 5 days after which mice were killed for heart excision and Langendorff perfusion (Peart and Gross, 2004; Peart et al., 2011), or further analysis. Serum morphine levels demonstrate a peak in the initial 0-24 $\mathrm{h}$ concentration, then a gradual decline for the remaining 4 days (Bryant et al. 1988). In our hands, the dosage of the slow-release pellets equates to $\sim 100 \mathrm{mg} / \mathrm{kg} / \mathrm{day}$. Mice were closely monitored daily to assess animal welfare post pellet implantation by animal facility staff and investigators.

\subsection{In Vivo Heart Rate Assessment}

Mice were anaesthetised very briefly with $3 \%$ isoflurane and restrained on a warmed platform with laboratory tape. ECG electrodes were inserted subcutaneously at right foreleg and left hind leg, then isoflurane was turned to 0 and heart rate was recorded at $20 \mathrm{~s}$ intervals for 3 min (10 measurements). Readings taken when animal was moving were excluded. ECG was monitored using the VisualSonics Vevo 2100 system. Readings were averaged for each animal.

\subsection{Heart Perfusions}

Mice were anaesthetised with sodium pentobarbital ( $60 \mathrm{mg} / \mathrm{kg}$ i.p.) and hearts excised, then Langendorff-perfused with Krebs-Henseleit buffer delivered via the aorta at a pressure of 80 $\mathrm{mmHg}$, as previously described (Headrick et al., 2001). Pyruvate ( $2 \mathrm{mM}$ ) was added to the Krebs-Henselet buffer for isoproterenol experiments to ensure stable contractile function. Briefly, hearts were cannulated and underwent 20 min unpaced stabilization. Hearts were then paced at 420 BPM for $10 \mathrm{~min}$, followed by $25 \mathrm{~min}$ global ischemia and $45 \mathrm{~min}$ reperfusion. Ventricular pacing was terminated upon the onset of ischaemia, and reinitiated after 2 min of reperfusion. A sub-set of hearts from the placebo-pellet ( \pm atenolol) mice were subjected to IPC, induced by $3 \times 1.5 \mathrm{~min}$ ischemia/ $2 \mathrm{~min}$ reperfusion cycles prior to the index ischemia. Coronary venous effluent was collected on ice throughout reperfusion, with samples assayed enzymatically for LDH. Total post-ischaemic efflux is reported as total LDH units (U/g). For concentration-response experiments with isoproterenol, after the stabilization period and IPC protocol (where relevant), hearts received single doses of isoproterenol $(1 \mathrm{nM}-10 \mu \mathrm{M})$ every $10 \mathrm{~min}$. Hearts are excluded from the study if they meet one of the following exclusion criteria after stabilization: i) coronary flow $>5 \mathrm{ml} / \mathrm{min}$, ii) 
unstable (fluctuating) contractile function, iii) left ventricular systolic pressure $<100 \mathrm{mmHg}$, or iv) significant cardiac arrhythmias. No hearts were excluded in this study.

\subsection{Statistical Analysis}

All data are expressed as means \pm S.E.M. Differences between groups were tested via oneway ANOVA, with a Newman-Keuls post hoc test applied when significant effects were detected. Significant differences were accepted for $\mathrm{P}<0.05$. All Statistics were performed with Prism 6 (GraphPad Software Inc., La Jolla, CA).

\section{Results}

\subsection{Isoproterenol-Concentration Response Studies}

Atenolol treatment (4 weeks) significantly reduced in vivo heart rate (Fig. 1). SLP also significantly reduced in vivo heart rate independent of atenolol-treatment (Fig. 1). Further, the combination of atenolol and SLP had additive effects in terms of the reduction of in vivo heart rate. Atenolol, SLP and IPC all produced a significant, and similar, reduction in the maximal response to isoproterenol-induced elevation of heart rate (Fig. 2). No additive/ synergistic actions of any further combinations of treatments were noted. $\mathrm{EC}_{50}$ from isoproterenol curves shows no significant alterations to functional sensitivities in the presence of atenolol in non-SLP hearts. The combination of atenolol and SLP appears to sensitise hearts to the chronotropic effects of isoproterenol, while desensitising inotropic responses (Table 1). Unlike SLP hearts, when combined with atenolol, IPC did not significantly alter chronotropic or inotropic responses (heart rate, LVDP, $+\mathrm{dP} / \mathrm{dt}$ ). Interestingly, the combination of chronic atenolol and acute IPC significantly sensitised the hearts lusitropic response to isoproterenol. It is unclear as to why this permutation of treatments modified this particular response.

\subsection{Ischemia-Reperfusion Studies}

No significant differences in baseline ex vivo cardiac function were identified between hearts, regardless of treatment ( \pm atenolol, morphine, vehicle) (Table 2). Ischaemic insult resulted in significant depression of contractile function in untreated hearts, with $\sim 50 \%$ recovery of left ventricular pressure development and a sustained $25 \mathrm{mmHg}$ elevation in diastolic pressure (Fig. 3). IPC and SLP both attenuated IR injury, reducing all aspects of contractile dysfunction (Fig. 3) and limiting post-ischaemic LDH efflux (Fig. 4), without any change to the recovery of coronary flow (Fig. 5). Recovery of coronary flow (\% baseline) was not different between groups, with the exception of a difference between IPC and atenolol with SLP (Fig. 5). The beneficial effects of SLP were modestly superior to those induced by IPC. Atenolol treatment alone was found to substantially worsen functional outcomes from IR whereas LDH efflux was not significantly modified. The cardioprotection with IPC was entirely abrogated by atenolol, whereas SLP-induced protection appeared resistant to the inhibitory effects of atenolol treatment (Figs. 3 and 4). 


\section{Discussion}

This study demonstrates that sustained $\beta_{1}$-adrenoceptor antagonism abolishes cardioprotection afforded by IPC without compromising novel SLP-mediated protection. Atenolol pre-treatment exerts negative effects on post-ischaemic function. Since $\beta$-blockers are used in up to $95 \%$ of AMI patients in the USA (Floyd et al., 2009), any acute interventions to limit IR injury/infarction should be refractory to the effects of $\beta$-blockade. Recent clinical trials of pre- and post-conditioning evidence some efficacy in AMI, though outcomes are modest relative to profound protection experimentally (Ludman et al., 2010). Whether these outcomes are influenced by chronic or acute $\beta$-blockade remains unclear. Thibault et al. (2008) detected a $40 \%$ infarct size reduction at $1 \mathrm{yr}$ in post-conditioned subjects, where prior $\beta$-blocker use was not reported (though $>80 \%$ received $\beta$-blockers by discharge). Lønborg et al. (2010) achieved 19\% infarct reduction at 3 months, with $20 \%$ of subjects receiving $\beta$-blockers at admission. Trialling remote pre-conditioning, $B \emptyset t k e r$ et al. (2010) detected $40 \%$ reduction in 30-day infarct size in patients not acutely treated with $\beta$ blockers (and for whom prevalence of chronic $\beta$-blockade was not reported). It is thus unclear what impact $\beta$-blockade may have in such trials. Critically, experimentation identifies opposing effects of $\beta$-blockade on IR outcomes in animal models, and potential inhibition of multiple protective responses.

\section{1 $\beta_{1}$-Adrenoceptor Antagonism, SLP and Functional Responses}

In the current study, prolonged atenolol treatment significantly reduced in vivo heart rate (Fig. 1). Sensitivity to isoproterenol in isolated-perfused hearts reveals a general reduction in maximal heart rate responses following atenolol treatment (Fig. 2). Subjecting mice to SLP also reduced maximal heart rate responses (only in control and not atenolol group, Fig. 2). Analysis of $\mathrm{EC}_{50}$ values suggests general treatment effects, however no significant intergroup differences were identified, except for apparent atenolol-dependent desensitisation of LVDP in SLP hearts (Table 1). Since isoproterenol responses were assessed ex vivo in the absence of acute $\beta$-blockade, and atenolol is rapidly washed out (based on $0 \%$ inhibition in $<30$ min of tissue perfusion, Hosohata et al., 1995), these functional changes likely reflect phenotypic changes associated with prolonged $\beta_{1}$-adrenoceptor antagonism.

Similar to atenolol, SLP also significantly reduced in vivo heart rate and maximal heart rate response to isoproterenol. Opioids reportedly decrease the spontaneous beating rate of isolated rat atria (Wong and Ingenito, 1993), and induce bradycardia through increasing vagal tone in anaesthetised dogs (Urthaler et al., 1975). While in vivo responses may be modulated by vagal tone, in vitro responses may involve inhibitory 'cross-talk' between opioid receptors and $\beta$-adrenoceptors. Indeed, $\delta$-opioid receptor antagonist leucineenkephalin, significantly reduces contractile responses to norepinephrine in isolated rat heart, in a pertussis toxin-sensitive manner (Pepe et al., 1997). Moreover, leucine-enkephalin demonstrates antiadrenergic effects in ventricular myocytes (Xiao et al., 1997).

\section{2 $\beta_{1}$-Adrenoceptor Antagonism and Intrinsic IR Tolerance}

Chronic $\beta$-blockade could influence IR tolerance since intrinsic $\beta_{1}$-adrenoceptor activity may contribute to myocardial injury (Arnold et al., 2007; Park et al., 2011; Spear et al., 
2007), whereas $\beta_{2}$-adrenoceptors contribute to cardioprotection (Peart and Gross, 2006; Tong et al, 2005; Xu et al., 2010; Zhang et al., 2010). Clinical trials indicate that early $\beta$ adrenoceptor blockade (within 4-6 hs of symptoms) can reduce infarct development (Herlitz et al., 1988; Yusuf et al., 1983). However, differing roles and drug selectivity for $\beta_{1}$ Vs. $\beta_{2^{-}}$ adrenoceptors, contributions from cardiac vs. extra-cardiac effects, and involvement of nonspecific actions ( $e g . \beta$-adrenoceptor independent anti-oxidant effects), render the basis of such outcomes unclear. Interestingly, meta-analyses fail to identify significant mortality effects of $\beta$-adrenoceptor blockade in AMI (Brandler et al., 2010; Perez et al., 2009) or protection against mortality in angina patients (Huang and Fox, 2012). Atenolol is a second generation $\beta_{1}$-adrenoceptor selective antagonist commonly prescribed in hypertensives, though there is minimal evidence that $\beta$-blockers reduce risk of AMI in hypertension (Wiysonge et al., 2007), and they are inferior in controlling associated hypertrophy and heart failure (Bangalore et al., 2008; Klingbeil et al., 2003). Contrasting evidence of $\beta_{1^{-}}$ adrenoceptor mediated cardiac injury (Arnold et al., 2007; Park et al., 2011; Spear et al., 2007), we detect impairment of contractile recovery from IR in atenolol-treated hearts (Fig. 3). This supports $\beta_{1}$-adrenoceptor dependence of myocardial IR resistance (Arnold et al., 2007; Park et al., 2011), an effect evident in isolation from extra-cardiac effects on autonomic control and cardiac loading in vivo. This may reflect the ability of $\beta_{1^{-}}$ adrenoceptor activity to promote protective signalling (Lange et al., 2006; Salie et al., 2011).

Disparate observations have been made regarding effects of chronic $\beta$-blockade on IR tolerance. Mallet et al. (2006) found no change in IR tolerance with chronic metoprolol in an in vivo canine model, whereas Suematsu and colleagues $(2002,2004)$ observed improved IR tolerance in ex vivo rat hearts following chronic treatment with non-selective nipradilol and propranolol. Our data, in contrast, evidence worsened IR tolerance with chronic $\beta_{1^{-}}$ adrenoceptor blockade. Reasons for these differing outcomes are unclear, though may relate to differing $\beta_{1} / \beta_{2}$ selectivity together with non-specific protective actions of different $\beta$ adrenoceptor antagonists.

Indeed, non-specific actions may be key to cardioprotection with many $\beta$-blockers. Nipradilol triggers protective NO release, and both nipradilol and propranolol exert powerful anti-oxidant effects that can protect the heart (Khaper et al., 1997; Suematsu et al., 2004). Carvedilol reduces infarction/cell death via anti-oxidant, -apoptotic, and -neutrophil functions independently of $\beta$-adrenoceptor blockade (Feuerstein et al., 1998; Schwarz et al., 2003), and cardioprotective effects of $\beta_{1}$-selective celiprolol and landiolol are also attributed to anti-oxidant actions (Chen et al., 2007; Kimura-Kurosawa et al., 2007).

\section{3 $\beta_{1}$-Adrenoceptor Antagonism and IPC}

There is some support for $\beta_{1}$-adrenoceptor involvement in protective signalling (Lange et al., 2006; Salie et al., 2011), and the current data indicate that prolonged $\beta_{1}$-adrenoceptor blockade is detrimental (Fig. 3). $\beta$-adrenoceptor activity may contribute to cardioprotection via modulation of PKC (Yabe et al., 1998), PKA (Bokník et al., 2001), p38-MAPK (Marais et al., 2001), and adenosine receptor signalling (Asanuma et al., 2004). Chronic $\beta$-blockade thus can interfere with cardioprotective signalling, a possibility supported by the current 
data. Whereas IPC limited IR injury in control hearts, atenolol pre-treatment negated the protective efficacy of IPC (Figs. 3 and 4).

This inhibitory effect of prolonged $\beta$-adrenoceptor blockade is consistent with effects of acute antagonism, which support $\beta$-adrenoceptor involvement in cardiac conditioning responses. Previous studies in rat (Lochner et al., 1999) and rabbit (Spear et al., 2007) hearts have demonstrated inhibition of IPC with $\beta_{1} / \beta_{2}$-adrenoceptor and $\beta_{1}$-adrenoceptor antagonism. Lange and colleagues (2006) report that acute $\beta_{1}$-adrenoceptor blockade negates anaesthetic preconditioning and partially limits IPC. These studies implicate $\beta$ adrenoceptor activity (likely the $\beta_{1}$-adrenoceptor sub-type) in acute preconditioning, though evidence exists of IPC resistance to acute $\beta$-blockade (Iliodromitis et al., 2004). The effects of chronic $\beta$-blockade are ambiguous. Mallet et al. (2006) found that $\beta_{1}$-adrenoceptor selective metoprolol (25 days) eliminated infarct-sparing effects of intermittent hypoxic preconditioning, and Suematsu and colleagues $(2002,2004)$ report abolition of IPC following 28 days of non-selective propranolol and nipradilol treatment. These studies and our data (Figs. 3 and 4) indicate that prior $\beta$-adrenoceptor antagonism impairs or eliminates protection via conventional preconditioning stimuli, implicating $\beta_{1}$-adrenoceptors in initiation or transduction of IPC. This raises the possibility of negative interactions between $\beta$-blockers commonly applied prior to or during AMI and cardioprotective interventions engaging conditioning/RISK mechanisms.

\section{4 $\beta_{1}$-Adrenoceptor Antagonism and SLP}

The above studies (Mallet et al., 2006; Spear et al., 2007; Suematsu et al., 2004) and current findings (Figs. 3 and 4) indicate that unconventional cardioprotective approaches are necessary, since common pharmacotherapies can impair conventional conditioning responses. Novel SLP is a potent cardioprotective therapy induced within 48 hours, and protection persists for up to 7 days post-stimulus withdrawal (Peart et al., 2011). Protection is induced via several days of low-level $\delta$-opioid receptor agonism (eliminating undesirable systemic effects of other opioid receptor subtypes), involves PI3K signalling in the initial induction phase, and $\beta_{2}$-adrenoceptor/PKA-dependent protective signalling during subsequent IR (Peart and Gross, 2006; Peart et al., 2011). This phenotype may be induced via non-opioidergic GPCRs, and is additive with adenosinergic protection (Peart et al., 2011). Additionally, SLP protection arises independently of cardioprotective caveolae/ caveolin-3 expression, and is less sensitive to cholesterol depletion than conventional cardioprotective therapies (See Hoe et al., 2014). The SLP response improves IR tolerance in young and aged myocardium (Peart and Gross, 2004), whereas IPC and post-conditioning interventions are impaired in older hearts (Peart and Headrick, 2009). These cardioprotective features of SLP highlight a distinct mechanistic basis promoting effectiveness of SLP in clinically-relevant models (age and disease, and here with chronic $\beta$-blockade) where current protective interventions consistently fail (Peart and Headrick, 2009). We here show that SLP is resistant to inhibitory effects of chronic $\beta_{1}$-blockade. This is consistent with insensitivity of SLP to acute $\beta_{1}$-adrenoceptor blockade (Peart et al., 2006). These findings demonstrate that neither opioidergic induction of SLP nor subsequent mediation of protection during IR is dependent upon $\beta_{1}$-adrenoceptor activity, while mediation may involve $\beta_{2}$-adrenoceptor signalling (Peart and Gross, 2006). Effectiveness across age groups 
and resistance to $\beta$-blockade render mechanisms of SLP more rational targets for induction of clinical cardioprotection, though currently the experimental strategy is restricted to preischaemic induction. Further research is required to identify specific underlying mechanisms and assess their potential utility and efficacy in reperfused myocardium.

\subsection{Study Limitations}

The data, as presented, contain some limitations. Firstly, the dose of atenolol utilised is higher than therapeutic doses $(0.5 \mathrm{~g} / \mathrm{L}$ in drinking water, replicated from Chung et al., 2008 where mice were given atenolol for $>6$ weeks). Despite no visible change to in-cage activity and an LD50 of $2000 \mathrm{mg} / \mathrm{mg}$, potential cardiotoxic effects or influences of hemodynamic changes cannot be ignored. We report no significant difference in heart rate or left ventricular developed pressure (or any parameter) at baseline (ex vivo), with an observed decrease in in vivo heart rate. A recent study (Berthonneche et al., 2009), with 2 week treatment with 7-fold lower atenolol dose reports $\sim 22 \%$ and $15 \%$ reductions in heart rate and systolic pressure, respectively, in vivo. Williams et al., (2003), report that 5 day treatment of $25 \mathrm{mg} / \mathrm{kg} /$ day atenolol had no effect on MAP with an $11 \%$ reduction in heart rate in C57BL/6J mice. The high dose of atenolol in our study would likely result in non-selective binding, most commonly with $\beta_{2}$-adrenoceptor. Interestingly, SLP, previously been shown to be $\beta_{2}$-adrenoceptor sensitive (Peart et al., 2006), was unaffected by atenolol treatment. Expression of both $\beta_{1}$ and $\beta_{2}$-adrenoceptors were assessed via western blot, with no change in the expression observed in the presence of atenolol (data not shown). However, as this was assessed at the termination of reperfusion as opposed to pre-ischemia, cautious interpretation is required. Whether results here would be replicated with significantly lower doses approximating therapeutic treatment is unknown, as such the results should be interpreted with this in mind. Further, it is unclear if the outcomes of the current study in young normotensive mice would correlate with the clinical situation where patients receiving $\beta$-blockers likely have cardiovascular disease and/or high sympathetic drive.

Secondly, the current study does not address the influence of $\beta$-blockade on cardioprotective signalling or downstream actions of $\beta_{1}$-adrenoceptor. Prior studies reveal that $\beta_{1^{-}}$ adrenoceptor is coupled to ERK signalling (Tilley et al., 2009; Zheng et al., 2010) through EGFR (Tilley et al., 2009) and $\beta$-arrestin (Nakaya et al., 2012; Tilley et al., 2009), and may be associated with MMP regulation (Chung et al., 2008), factors known to influence IPC and cardioprotection (Hausenloy et al., 2005; Williams-Pritchard et al., 2011). Further work is required to interrogate the detailed molecular mechanisms.

Though well documented, the Langendorff perfusion method to assess ex vivo cardiovascular function is not devoid of limitations. An in vivo approach assessing infarction may have provided alternative results due to circulating metabolic and/or neuro-humoral influences that are absent in the ex vivo heart. Nonetheless, the Langendorff provides evidence of direct effects upon the cardiac phenotype.

\subsection{Conclusions}

In summary, our data suggest that $\beta_{1}$-adrenoceptor activation is essential to IPC, yet not involved in induction of SLP protection. Chronic $\beta_{1}$-blockade may also exert negative 
effects on intrinsic IR tolerance. These findings support complex effects of $\beta$-adrenoceptor activity on IR outcomes, and highlight the importance of considering effects of common pharmaceuticals when developing interventions to myocardial IR injury.

\section{Acknowledgments}

Sources of Funding

This work was supported by a Heart Foundation Grant-in-Aid (JP, JH). JP was the recipient of a Future Fellowship from the Australian Research Council (FT100100695). LS is the recipient of a National Heart Foundation Postgraduate Scholarship (PB 12B 6956). In addition to grants from the National Institutes of Health HL091071 (HHP), HL107200 (HHP, DMR), HL066941 (DMR, HHP), and HL115933 (DMR), and VA Merit BX001963 (HHP) and BX000783 (DMR).

\section{REFERENCES}

Arnold AS, Tang YL, Qian K, Shen L, Valencia V, Phillips MI, et al. Specific $\beta 1$-adrenergic receptor silencing with small interfering RNA lowers high blood pressure and improves cardiac function in myocardial ischemia. J Hypertens. 2007; 25:197-205. [PubMed: 17143192]

Asanuma H, Minamino T, Sanada S, Takashima S, Ogita H, Ogai A, et al. $\beta$-adrenoceptor blocker carvedilol provides cardioprotection via an adenosine-dependent mechanism in ischemic canine hearts. Circulation. 2004; 109:2773-2779. [PubMed: 15148268]

Bangalore S, Wild D, Parkar S, Kukin M, Messerli FH. $\beta$-blockers for primary prevention of heart failure in patients with hypertension: insights from a meta-analysis. J Am Coll Cardiol. 2008; 52:1062-1072. [PubMed: 18848139]

Berthonneche C, Peter B, Schüpfer F, Hayoz P, Kutalik Z, Abriel H, et al. Cardiovascular response to beta-adrenergic blockade or activation in 23 inbred mouse strains. PLoS One. 2009; 4:e6610. [PubMed: 19672458]

Bokník P, Khorchidi S, Bodor GS, Huke S, Knapp J, Linck B, et al. Role of protein phosphatases in regulation of cardiac inotropy and relaxation. Am J Physiol Heart Circ Physiol. 2001; 280:H786H794. [PubMed: 11158978]

Bøtker HE, Kharbanda R, Schmidt MR, Bøttcher M, Kaltoft AK, Terkelsen CJ, et al. Remote ischaemic conditioning before hospital admission, as a complement to angioplasty, and effect on myocardial salvage patients with acute myocardial infarction: a randomized trial. Lancet. 2010; 375:729-734.

Brandler E, Paladino L, Sinert R. Does the early administration of beta-blockers improve the inhospital mortality rate of patients admitted with acute coronary syndrome? Acad Emerg Med. 2010; 17:1-10. [PubMed: 20078433]

Bryant HU, Yoburn BC, Inturrisu CE, Bernton EW, Holaday JW. Morphine-induced immunomodulation is not related to serum morphine concentrations. Eur J Pharmacol. 1988; 149:165-9. [PubMed: 3260867]

Chen X, Minatoguchi S, Arai M, Wang N, Lu C, Narentuoya B, et al. Celiprolol, a selective beta1blocker, reduces the infarct size through production of nitric oxide in a rabbit model of myocardial infarction. Circ J. 2007; 71:574-579. [PubMed: 17384462]

Chung AW, Yang HH, Radomski MW, van Breemen C. Long-term doxycycline is more effective than atenolol to prevent thoracic aortic aneurysm in marfan syndrome through the inhibition of matrix metalloproteinase-2 and -9. Circ Res. 2008; 102:e73-85. [PubMed: 18388324]

Ferdinandy P, Schulz R, Baxter GF. Interaction of cardiovascular risk factors with myocardial ischemia/reperfusion injury, preconditioning, and postconditioning. Pharmacol Rev. 2007; 59:418458. [PubMed: 18048761]

Feuerstein G, Yue TL, Ma X, Ruffolo RR. Novel mechanisms in the treatment of heart failure: inhibition of oxygen radicals and apoptosis by carvedilol. Prog Cardiovasc Dis. 1998; 41:17-24. [PubMed: 9715819] 
Floyd KC, Yarzebski J, Spencer FA, Lessard D, Dalen JE, Alpert JS, et al. A 30-year perspective (1975-2005) into the changing landscape of patients hospitalized with initial acute myocardial infarction: Worcester Heart Attack Study. Circ Cardiovasc Qual Outcomes. 2009; 2:88-95. [PubMed: 20031820]

Freemantle N, Cleland J, Young P, Mason J, Harrison J. Beta-blockade after myocardial infarction: systematic review and meta regression analysis. BMJ. 1999; 318:1730-1737. [PubMed: 10381708]

Frishman WH, Furberg CD, Friedewald WT. Beta-adrenergic blockade for survivors of acute myocardial infarction. N Engl J Med. 1984; 310:830-837. [PubMed: 6142420]

Headrick JP, Peart JN, Hack B, Flood A, Matherne GP. Functional properties and responses to ischemia-reperfusion in Langendorff perfused mouse heart. Exp Physiol. 2001; 86:703-716. [PubMed: 11698964]

Herlitz J, Waldenström J, Hjalmarson A. Infarct size limitation after early intervention with metoprolol in the MIAMI Trial. Cardiology. 1988; 75:117-122. [PubMed: 3370654]

Huang HL, Fox KA. The impact of beta-blockers on mortality in stable angina: a meta-analysis. Scott Med J. 2012; 57:69-75. [PubMed: 22555225]

Hausenloy DJ, Yellon DM. New directions for protecting the heart against ischemia-reperfusion injury: targeting the reperfusion injury salvage kinase (RISK) pathway. Cardiovasc Res. 2004; 61:448460. [PubMed: 14962476]

Hausenloy DJ, Tsang A, Mocanu MM, Yellon DM. Ischemic preconditioning protects by activating prosurvival kinases at reperfusion. Am J Physiol Heart Circ Physiol. 2005; 288:H971-6. [PubMed: 15358610]

Hosohata Y, Sasaki K, Shen Y, Hattori K, Suzuki J, Nagatomo T. Bopindolol Is a Slowly Dissociating $\beta_{1}$-Adrenoceptor Antagonist When Compared to Other $\beta$-Blockers. Bio Pharm Bull. 1995; 18:1066-1071. [PubMed: 8535397]

Iliodromitis EK, Tasouli A, Andreadou I, Bofilis E, Zoga A, Cokkinos P, et al. Intravenous atenolol and esmolol maintain the protective effect of ischemic preconditioning in vivo. Eur $\mathrm{J}$ Pharmacol. 2004; 499:163-169. [PubMed: 15363963]

Khaper N, Rigatto C, Seneviratne C, Li T, Singal PK. Chronic treatment with propranolol induces antioxidant changes and protects against ischemia-reperfusion injury. J Mol Cell Cardiol. 1997; 29:3335-3344. [PubMed: 9441839]

Kimura-Kurosawa S, Kanaya N, Kamada N, Hirata N, Nakayama M, Namiki A. Cardioprotective effect and mechanism of action of landiolol on the ischemic reperfused heart. J Anesth. 2007; 21:480-489. [PubMed: 18008115]

Klingbeil AU, Schneider M, Martus P, Messerli FH, Schmieder RE. A meta-analysis of the effects of treatment on left ventricular mass in essential hypertension. Am J Med. 2003; 115:41-46. [PubMed: 12867233]

Kloner RA, Schwartz Longacre L. State of the science of cardioprotection: Challenges and opportunities--proceedings of the 2010 NHLBI Workshop on Cardioprotection. J Cardiovasc Pharmacol Ther. 2011; 16:223-232. [PubMed: 21821520]

Lange M, Smul TM, Blomeyer CA, Redel A, Klotz KN, Roewer N, et al. Role of the beta1-adrenergic pathway in anesthetic and ischemic preconditioning against myocardial infarction in the rabbit heart in vivo. Anesthesiology. 2006; 105:503-510. [PubMed: 16931983]

Lochner A, Genade S, Tromp E, Podzuweit T, Moolman JA. Ischemic preconditioning and the betaadrenergic signal transduction pathway. Circulation. 1999; 100:958-966. [PubMed: 10468527]

Lønborg J, Kelbaek H, Vejlstrup N, Jørgensen E, Helqvist S, Saunamäki K, et al. Cardioprotective effects of ischemic postconditioning in patients treated with primary percutaneous coronary intervention, evaluated by magnetic resonance. Circ Cardiovasc Interv. 2010; 3:34-41. [PubMed: 20118154]

Ludman AJ, Yellon DM, Hausenloy DJ. Cardiac preconditioning for ischemia: lost in translation. Dis Model Mech. 2010; 3:35-38. [PubMed: 20075380]

Mallet RT, Ryou MG, Williams AG Jr, Howard L, Downey HF. $\beta 1$-Adrenergic receptor antagonism abrogates cardioprotective effects of intermittent hypoxia. Basic Res Cardiol. 2006; 101:436-446. [PubMed: 16705468] 
Marais E, Genade S, Strijdom H, Moolman JA, Lochner A. p38 MAPK activation triggers pharmacologically induced $\beta$-adrenergic preconditioning, but not ischaemic preconditioning. $\mathbf{J}$ Mol Cell Cardiol. 2001; 33:2157-2177. [PubMed: 11735262]

Mei J, Yu S, Ahrén B. Study on administration of 1,5-anhydro-D-fructose in C57BL/6J mice challenged with high-fat diet. BMC Endocr Disord. 2010; 10:17. [PubMed: 20958989]

Nakaya M, Chikura S, Watari K, Mizuno N, Mochinaga K, Mangmool S, et al. Induction of cardiac fibrosis by $\beta$-blocker in $\mathrm{G}$ protein-independent and GRK5/ $\beta$-arrestin2-dependent signaling pathways. J Biol Chem. 2012; 287:35669-77. [PubMed: 22888001]

Park H, Otani H, Oishi C, Fujikawa M, Yamashita K, Okazaki T, et al. Efficacy of intracoronary administration of a short-acting $\beta$-blocker landiolol during reperfusion in pigs. Int $\mathrm{J}$ Cardiol. 2011; 146:347-353. [PubMed: 19709770]

Peart JN, Headrick JP. Clinical cardioprotection and the value of conditioning responses. Am J Physiol Heart Circ Physiol. 2009; 296:H1705-H1720. [PubMed: 19363132]

Peart JN, Gross GJ. Chronic exposure to morphine produces a marked cardioprotective phenotype in aged mouse hearts. Exp Gerontol. 2004; 39:1021-1026. [PubMed: 15236761]

Peart JN, Gross GJ. Cardioprotective effects of acute and chronic opioid treatment are mediated via different signaling pathways. Am J Physiol Heart Circ Physiol. 2006; 291:H1746-H1753. [PubMed: 16731654]

Peart JN, See Hoe LE, Gross GJ, Headrick JP. Sustained ligand-activated preconditioning via deltaopioid receptors. J Pharmacol Exp Ther. 2011; 336:274-281. [PubMed: 20947639]

Pepe S, Xiao RP, Hohl C, Altschuld R, Lakatta EG. 'Cross talk' between opioid peptide and adrenergic receptor signaling in isolated rat heart. Circulation. 1997; 95:2122-9. [PubMed: 9133523]

Perez MI, Musini VM, Wright JM. Effect of early treatment with anti-hypertensive drugs on short and long-term mortality in patients with an acute cardiovascular event. Cochrane Database Syst Rev. 2009; 4:CD006743. [PubMed: 19821384]

Salie R, Moolman JA, Lochner A. The role of $\beta$-adrenergic receptors in the cardioprotective effects of beta-preconditioning ( $\beta$ PC). Cardiovasc Drugs Ther. 2011; 25:31-46. [PubMed: 21225332]

Schwarz ER, Kersting PH, Reffelmann T, Meven DA, Al-Dashti R, Skobel EC, et al. Cardioprotection by Carvedilol: antiapoptosis is independent of beta-adrenoceptor blockage in the rat heart. $\mathrm{J}$ Cardiovasc Pharmacol Ther. 2003; 8:207-215. [PubMed: 14506546]

See Hoe LE, Schilling JM, Tarbit E, Kiessling CJ, Busija AR, Niesman IR, et al. Sarcolemmal cholesterol and caveolin-3 dependence of cardiac function, ischemic tolerance, and opioidergic cardioprotection. Am J Physiol Heart Circ Physiol. 2014; 307:H895-903. [PubMed: 25063791]

Spear JF, Prabu SK, Galati D, Raza H, Anandatheerthavarada HK, Avadhani NG. beta1Adrenoreceptor activation contributes to ischemia-reperfusion damage as well as playing a role in ischemic preconditioning. Am J Physiol Heart Circ Physiol. 2007; 292:H2459-H2466. [PubMed: 17237252]

Suematsu Y, Ohtsuka T, Horimoto H, Maeda K, Nakai Y, Mieno S, Takamoto S. Long-term treatment with nipradilol, a nitric oxide-releasing beta-adrenergic blocker, enhances postischemic recovery and limits infarct size. Ann Thorac Surg. 2002; 73:173-9. [PubMed: 11834008]

Suematsu Y, Anttila V, Takamoto S, del Nido P. Cardioprotection afforded by ischemic preconditioning interferes with chronic beta-blocker treatment. Scand Cardiovasc J. 2004; 38:293-299. [PubMed: 15513313]

Thibault H, Piot C, Staat P, Bontemps L, Sportouch C, Rioufol G, et al. Long-term benefit of postconditioning. Circulation. 2008; 26:1037-44. [PubMed: 18268150]

Tilley DG, Kim IM, Patel PA, Violin JD, Rockman HA. beta-Arrestin mediates beta1-adrenergic receptor-epidermal growth factor receptor interaction and downstream signalling. J Biol Chem. 2009; 284:20375-86. [PubMed: 19509284]

Tong H, Bernstein D, Murphy E, Steenbergen C. The role of beta-adrenergic receptor signalling in cardioprotection. FASEB J. 2005; 19:983-985. [PubMed: 15802488]

Urthaler F, Isobe JH, James TN. Direct and vagally mediated chronotropic effects of morphine studied by selective perfusion of the sinus node of awake dogs. Chest. 1975; 68:222-8. [PubMed: 238796] 
Williams TD, Chambers JB, Roberts LM, Henderson RP, Overton JM. Diet-induced obesity and cardiovascular regulation in C57BL/6J mice. Clin Exp Pharmacol Physiol. 2003; 30:769-78. [PubMed: 14516417]

Williams-Pritchard G, Knight M, Hoe LS, Headrick JP, Peart JN. Essential role of EGFR in cardioprotection and signaling responses to A1 adenosine receptors and ischemic preconditioning. Am J Physiol Heart Circ Physiol. 2011; 300:H2161-8. [PubMed: 21460200]

Wiysonge CS, Bradley H, Mayosi BM, Maroney R, Mbewu A, Opie LH, et al. $\beta$-blockers for hypertension. Cochrane Database Syst Rev. 2007; (1):CD002003. [PubMed: 17253471]

Wong SC, Ingenito AJ. Possible opioid receptor function changes in isolated atria of the spontaneously hypertensive rat. Gen Pharmacol. 1993; 24:1483-90. [PubMed: 8112524]

Xiao RP, Pepe S, Spurgeon HA, Capogrossi MC, Lakatta EG. Opioid peptide receptor stimulation reverses beta-adrenergic effects in rat heart cells. Am J Physiol. 1997; 272:H797-805. [PubMed: 9124441]

Xu C, Liu A, Sun H, Sun Y, Wang G, Gao L, et al. $\beta_{2}$-Adrenoceptor confers cardioprotection against hypoxia in isolated ventricular myocytes and the effects depend on estrogenic environment. $\mathrm{J}$ Recept Signal Transduct Res. 2010; 30:255-261. [PubMed: 20602544]

Yabe K, Ishishita H, Tanonaka K, Takeo S. Pharmacologic preconditioning induced by beta-adrenergic stimulation is mediated by activation of protein kinase C. J Cardiovasc Pharmacol. 1998; 32:962968. [PubMed: 9869502]

Yusuf S, Sleight P, Rossi P, Ramsdale D, Peto R, Furze L, et al. Reduction in infarct size, arrhythmias and chest pain by early intravenous beta blockade in suspected acute myocardial infarction. Circulation. 1983; 67:I32-41. [PubMed: 6851037]

Zhang Q, Xiang J, Wang X, Liu H, Hu B, Feng M, et al. $\beta 2$-adrenoceptor agonist clenbuterol reduces infarct size and myocardial apoptosis after myocardial ischemia/reperfusion in anaesthetized rats. Br J Pharmacol. 2010; 160:1561-1572. [PubMed: 20590644]

Zheng J, Shen H, Xiong Y, Yang X, He J. The beta1-adrenergic receptor mediates extracellular signalregulated kinase activation via Galphas. Amino Acids. 2010; 38:75-84. [PubMed: 19037712] 


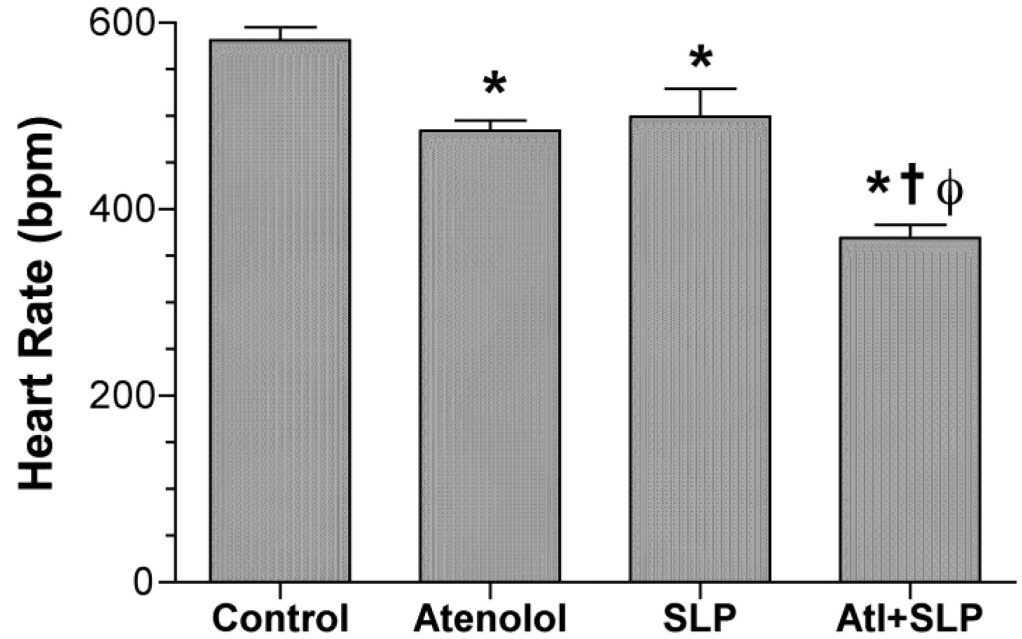

Fig. 1.

Effects of atenolol and SLP upon in vivo heart rates of control (untreated) vs. atenololtreated mice \pm SLP. Groups: untreated (Control, $n=13$ ), atenolol treated (Atenolol, $n=13$ ), and SLP in control (SLP, $n=14$ ) and atenolol-treated (Atl+SLP, $n=13$ ) hearts. Data are means \pm S.E.M *, P 0.05 vs. Control. $\dagger, \mathrm{P} \unlhd 0.05$ vs. Atenolol. $\Phi, \triangleleft 0.05$ vs. SLP. 


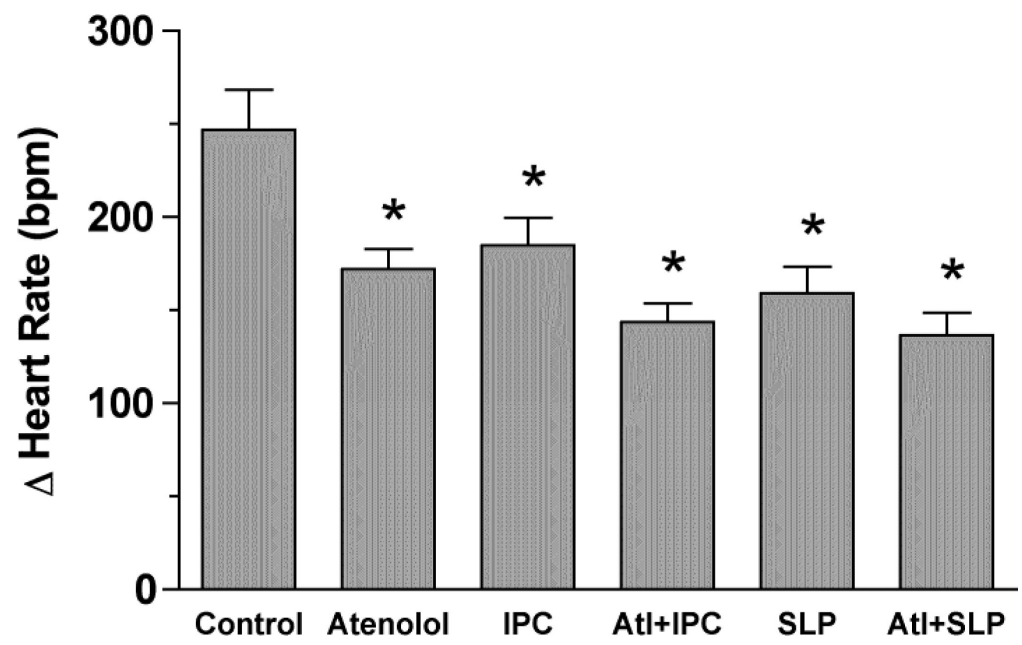

Fig. 2.

Change in maximal heart rate $(\Delta \mathrm{HR})$ upon challenge with isoproterenol in isolated hearts. Groups: untreated (Control, $n=13$ ), atenolol treated (Atenolol, $n=13$ ), IPC in control (IPC, $n=12$ ) and atenolol-treated (Atl+IPC, $n=12$ ) hearts, and SLP in control (SLP, $n=14$ ) and atenolol-treated (Atl+SLP, $n=13$ ) hearts. Data are expressed as means \pm S.E.M $* \mathrm{P}<0.05$ vs. Control (untreated). 
A

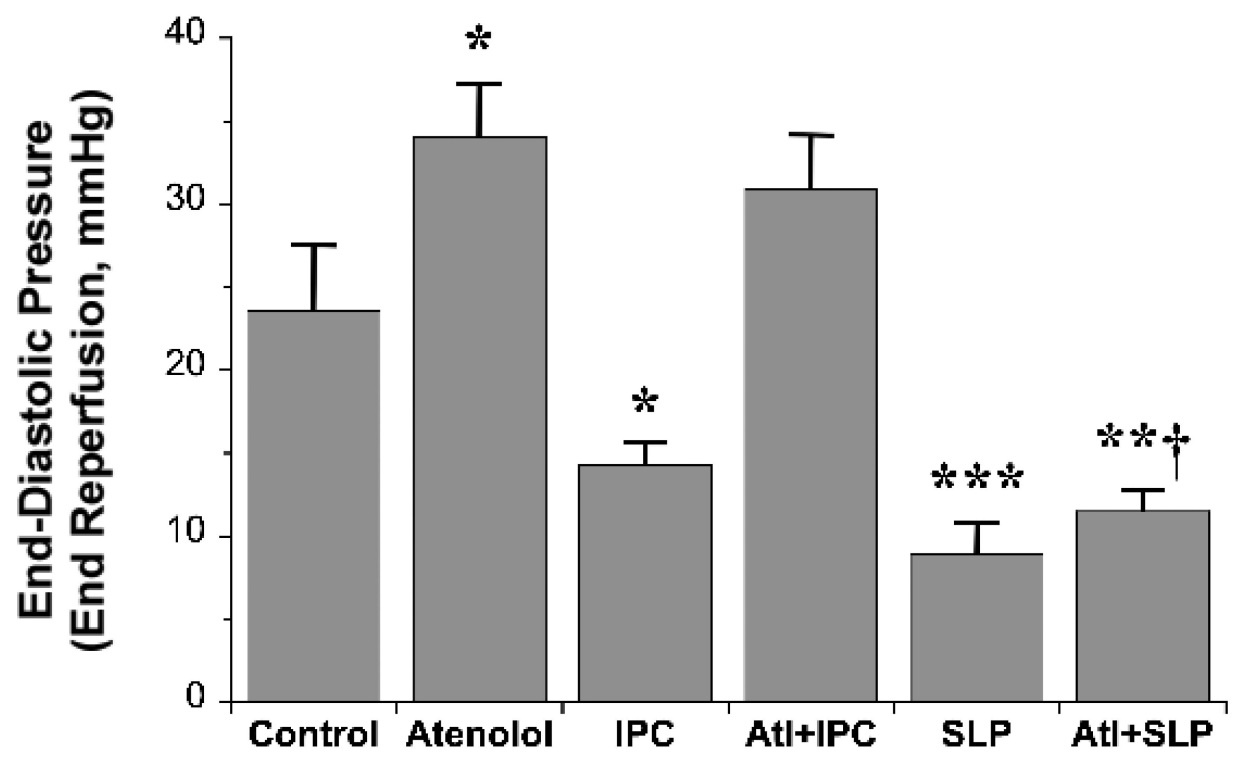

B

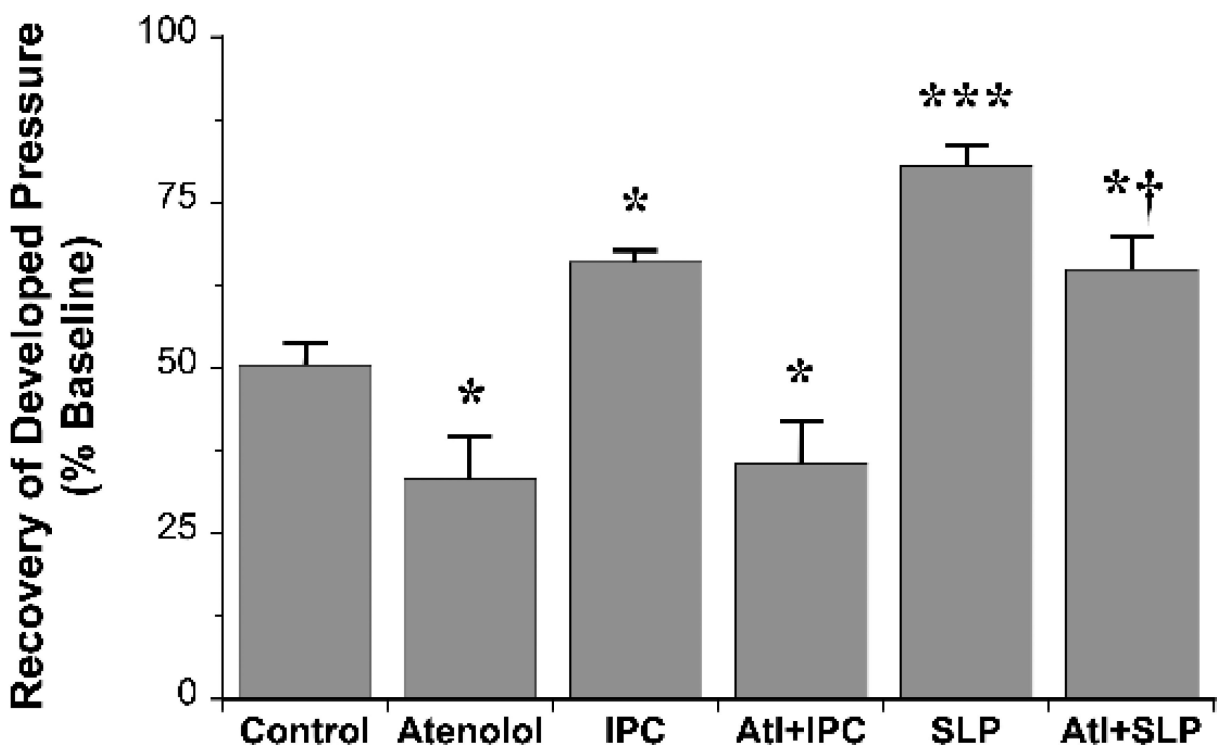

Fig. 3.

Effects of chronic atenolol on contractile dysfunction with IR, and functional protection via IPC and SLP at end of reperfusion. Functional outcomes were assessed in Langendorff hearts subjected to $25 \mathrm{~min}$ ischemia/45 min reperfusion. A, end diastolic pressure (LVEDP, $\mathrm{mmHg}$ ); B, recovery of left ventricular developed pressure (LVDP, \% preischemia). Groups: untreated (Control, $n=8$ ), atenolol treated (Atenolol, $n=6$ ), IPC in control (IPC, $n=8$ ) and atenolol-treated (Atl+IPC, $n=6$ ) hearts, and SLP in control (SLP, $n=7$ ) and atenolol-treated 
(Atl+SLP, $n=8$ ) hearts. Data are means \pm S.E.M. *, $\mathrm{P}<0.05 ; * *, \mathrm{P}<0.01 ; * * *, \mathrm{P}<0.001$ vs. Control. $\uparrow, \mathrm{P}<0.001$ vs. Atenolol. 




Fig. 4.

Effects of chronic atenolol on cell damage with IR (LDH efflux), and protection via IPC and SLP. LDH efflux (U/g) was measured throughout $45 \mathrm{~min}$ of reperfusion following $25 \mathrm{~min}$ ischemia. Groups: untreated (Control, $n=8$ ), atenolol treated (Atenolol, $n=6$ ), IPC in control (IPC, $n=8)$ and atenolol-treated (Atl+IPC, $n=6$ ) hearts, and SLP in control (SLP, $n=7$ ) and atenolol-treated (Atl+SLP, $n=8$ ) hearts. Data are means \pm S.E.M. *, $\mathrm{P}<0.05 ; * *, \mathrm{P}<0.01$; ***, $\mathrm{P}<0.001$ vs. Control. $\dagger, \mathrm{P}<0.001$ vs. Atenolol. 


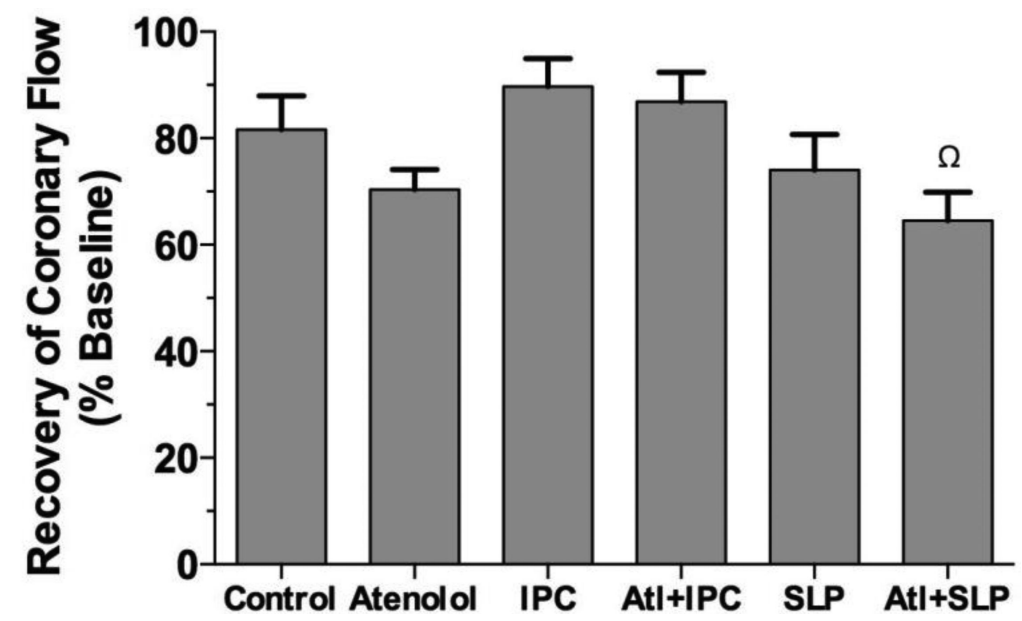

Fig. 5.

Recovery of coronary flow assessed following $25 \mathrm{~min}$ ischaemia and $45 \mathrm{~min}$ reperfusion.

Groups: untreated (Control, $n=8$ ), atenolol treated (Atenolol, $n=6$ ), IPC in control (IPC, $n=8$ ) and atenolol-treated (Atl+IPC, $n=6)$ hearts, and SLP in control (SLP, $n=7)$ and atenololtreated (Atl+SLP, $n=8$ ) hearts. Data are means \pm S.E.M. $\Omega, \mathrm{P}<0.05$ vs. IPC. 


\section{Table 1}

$\mathrm{EC}_{50}$ of hearts challenged with isoproterenol (nM).

\begin{tabular}{|c|c|c|c|c|}
\hline Group & Heart Rate & LVDP & $\mathbf{d P} / \mathbf{d t}_{\max }$ & $\mathbf{d P} / \mathbf{d t}_{\text {min }}$ \\
\hline Control $(n=13)$ & $98 \pm 20$ & $14 \pm 3$ & $27 \pm 7$ & $26 \pm 2$ \\
\hline $\operatorname{IPC}(n=12)$ & $79 \pm 17$ & $28 \pm 8$ & $21 \pm 4$ & $29 \pm 2$ \\
\hline $\operatorname{SLP}(n=14)$ & $75 \pm 10$ & $37 \pm 11$ & $21 \pm 6$ & $46 \pm 4^{b}$ \\
\hline Atenolol $(n=13)$ & $60 \pm 9$ & $32 \pm 20$ & $10 \pm 3$ & $27 \pm 2$ \\
\hline Atl+IPC $(n=12)$ & $87 \pm 12$ & $101 \pm 50$ & $12 \pm 3$ & $6 \pm 1^{b}$ \\
\hline $\operatorname{Atl}+\operatorname{SLP}(n=13)$ & $21 \pm 5^{b}$ & $297 \pm 106^{b}$ & $7 \pm 3^{a}$ & $33 \pm 7$ \\
\hline
\end{tabular}

Data are presented as means \pm S.E.M.

${ }^{a} \mathrm{P}<0.05$ vs. Control (untreated)

$b_{\mathrm{P}<0.05 \text { vs. all groups. }}$ 


\section{Table 2}

Baseline function in perfused hearts after 30 min normoxic stabilization (prior to any IPC stimulus, ischemia or reperfusion)

\begin{tabular}{ccccc}
\hline Group & LVEDP $(\mathbf{m m H g})$ & LVDP $(\mathbf{m m H g})$ & Heart Rate (beats/min) & Coronary Flow $(\mathbf{m l} / \mathbf{m i n})$ \\
\hline Control $(\boldsymbol{n}=\mathbf{8})$ & $3 \pm 1$ & $131 \pm 6$ & $419 \pm 3$ & $2.7 \pm 0.2$ \\
IPC $(\boldsymbol{n}=\mathbf{8})$ & $4 \pm 1$ & $130 \pm 6$ & $422 \pm 7$ & $3.1 \pm 0.4$ \\
SLP $(\boldsymbol{n}=\mathbf{7})$ & $2 \pm 1$ & $124 \pm 6$ & $417 \pm 12$ & $2.6 \pm 0.3$ \\
Atenolol $(\boldsymbol{n}=\mathbf{6})$ & $5 \pm 1$ & $113 \pm 6$ & $433 \pm 8$ & $3.1 \pm 0.2$ \\
Atl+IPC $(\boldsymbol{n}=\mathbf{6})$ & $4 \pm 1$ & $115 \pm 4$ & $421 \pm 10$ & $2.9 \pm 0.2$ \\
Atl+SLP $(\boldsymbol{n}=\mathbf{8})$ & $5 \pm 1$ & $125 \pm 9$ & $418 \pm 13$ & $3.0 \pm 0.2$ \\
\hline
\end{tabular}

Groups: untreated (Control), atenolol treated (Atenolol), IPC in control (IPC) and atenolol-treated (Atl+IPC) hearts, and SLP in control (SLP) and atenolol-treated (Atl+SLP) hearts. LVEDP and LVDP: left ventricular end-diastolic and developed pressures, respectively. Data are means \pm S.E.M. No differences in function were detected across groups upon langendorff perfusion. 